author's accepted manuscript, published in F. Buongiorno, V. Costa, R. Lanfredini (eds.), Phenomenology in Italy. Authors, Schools, Traditions. Dordrecht: Springer. The final publication is available at https://www.springer.com/gp/book/9783030253967

PLEASE QUOTE ONLY FROM PUBLISHED VERSION

Abstract: In this work, I discuss the role of Husserl's phenomenology in Paolo Parrini's positive philosophy. In the first section, I highlight the presence of both empiricist and constructivist elements in Parrini's anti-foundationalist and antiabsolutist conception of knowledge. In the second section, I stress Parrini's acknowledgement of the crucial role of phenomenology in investigating the empirical basis of knowledge, thanks to its analysis of the relationship between form and matter of cognition. In the third section, I point out some lines of development of the phenomenological form of empirical realism as revealed in Parrini's reflection, through a comparison of Husserl's genetic phenomenology, Mary Hesse's network model and the tradition of neutral monism.

Keywords: the problem of knowledge, realism and anti-realism, relativized a priori, form and matter of knowledge, Husserl and Kant, empirical realism, Mary Hesse's network model, Giulio Preti, genetic phenomenology, logical empiricism

\title{
Phenomenology, Empiricism, and Constructivism in Paolo Parrini's Positive Philosophy
}

\section{Introduction}

Paolo Parrini has developed a philosophical view that is based on the comparison between different schools of thought and on their integration into an original synthesis. Parrini follows his master Giulio Preti in bringing into dialogue, especially, Kantian philosophy, logical empiricism and Husserlian phenomenology. In this work, I shall highlight the role of phenomenology in some central aspects of Parrini's philosophy, arguing that Parrini's reading of phenomenology leads to a phenomenological form of empirical realism. In the first section, I shall highlight the presence of both empiricist and constructivist elements in Parrini's antifoundationalist and anti-absolutist conception of knowledge. In the second section, I shall stress Parrini's acknowledgement of the crucial role of phenomenology in 
investigating the empirical basis of knowledge, thanks to its analysis of the relationship between form and matter of cognition. In the third section, I shall concentrate on some lines of development of the phenomenological empirical realism that is revealed by Parrini's reflection, through a comparison of Husserl's genetic phenomenology, Mary Hesse's network model and the tradition of neutral monism.

\section{Positive Philosophy}

The expression "positive philosophy" refers to the philosophical view that is developed by Parrini in Knowledge and Reality (Parrini 1998), Sapere ed interpretare (Knowing and Interpreting, Parrini 2002), Il valore della verità (The Value of Truth, Parrini 2011) and in various other essays. Parrini distinguishes between the terms "positivistic" and "positive". The latter refers to a philosophical attitude that remains valid notwithstanding the crisis of the positivistic philosophies of the past and that consists in problematizing every alleged absolute knowledge.

Positive philosophy is developed as an alternative to two opposite philosophical views that can be found in the history of philosophy and in recent epistemological debates: radical relativism and metaphysical realism.

Within contemporary epistemology, radical relativism is the consequence of some views that are especially developed within the "new philosophy of science" and that take to the extreme the thesis of the "theory-ladenness of observation". These views claim that changes in the theories through which we aim at reaching objective knowledge of reality, lead to a change of reality itself. Therefore, radical relativism is the thesis that there are as many truths and realities as there are theories and conceptual frameworks through which we refer to reality and that these truths and realities are reciprocally "incommensurable".

Parrini acknowledges some virtues of these non-absolutistic conceptions of knowledge. At the same time, he argues that if radical relativism is the claim that truth is relative, it is self-contradictory. On the other hand, if radical relativism is just the statement of a personal conviction that lays no claims of intersubjective validity, it is philosophically irrelevant. For this reason, we must set a limit on the extent of relativism, by distinguishing between relativity of truth (aletic relativism) and relativity of the attributions of truth (epistemic relativism). Parrini thus denies the relativity of truth, arguing for a form of epistemic relativism that conceives of truth as a regulative ideal that guides our epistemic efforts (see Parrini 2015: 45).

At the same time, Parrini's positive philosophy is developed in contrast to the opposite of radical relativism, i.e. metaphysical realism. This is the view in contemporary epistemology that seeks to overcome the critiques of metaphysics developed by Kant and by the logical empiricists. This trend in contemporary philosophy is fueled by Willard Van Orman Quine's critique of the two dogmas of 
empiricism, which were at the basis of the reductionist version of the principle of verification. The crisis of logical empiricism has given up its place to a reprisal of metaphysics. Various forms of the renaissance of metaphysics in contemporary philosophy share the commitment to a view of knowledge as aimed at establishing a correspondence between ordo idearum and ordo rerum and therefore as aimed at "mirroring" an absolute reality "in itself". However, Parrini argues that these foundationalist and absolutist conceptions of knowledge risk legitimising their opposite, i.e. scepticism. This is because metaphysical realism defines the concept of reality as absolutely transcendent with respect to the act of knowing. In this way, it struggles with the difficulty of pointing at criteria that allow us to verify the correspondence between our knowledge claims and a reality that is absolutely transcendent with respect to them. On this point, Parrini draws on Preti's idea, that stressed the essential connection between radical scepticism and metaphysical realism:

"Until we remain stuck in an approach to the problem of knowledge that is conditioned by the "dogmatical" acceptance of a knowing subject that is opposed to the 'existence of a real world that is independent from the act of knowing', we cannot overcome the sceptical standpoint. It is this ontologically doomed approach that legitimates the sceptical standpoint [...]. This is especially clear when we consider the scholastic formula veritas est adaequatio rei et intellectus as the criterion of truth: our thinking does not contain any criterion for establishing the adaequatio because the criterion is outside, in the res. We must 'catch' and 'grasp' reality but we cannot ever know if 'we caught a real thing or a shadow'. For this reason, metaphysical realism and scepticism must be conceived as 'two faces of the same coin" (Parrini 2002: 72, my translation; the quotes are from Preti 1974: 3, 7, 12; my translation).

Following Preti, Parrini claims that the metaphysical realist "hands to the sceptic, on a silver platter, a standard of evaluation (the accordance with absolute reality or reality in itself) that our knowing is not able to satisfy because of the way it is structured (epistemic relativism)" (Parrini 2015: 44; my translation) ${ }^{1}$.

However, a crucial point distinguishes Parrini from Preti. By taking the principle of verification as the criterion of meaningfulness, Preti conceived of metaphysical realism as devoid of cognitive meaning. Parrini shares Preti's attempt at defusing radical scepticism by eradicating the metaphysical realism that is at its basis. At the same time, he seeks to develop an improved critique of metaphysical realism that takes into account the crisis of the principle of verification. This analysis is at the heart of Parrini's positive philosophy, which is based on three key concepts: moderate epistemic relativism, holistic empiricism, and empirical realism.

${ }^{1}$ According to Parrini, this applies also to those forms of metaphysical realism that adopt an attenuated version of correspondentism. 


\subsection{Moderate epistemic relativism}

Parrini develops an analysis of knowledge that takes into account the scientific revolutions that occurred between the nineteenth and the twentieth century. This analysis leads Parrini to acknowledge the existence of various kinds of presuppositions of the cognitive process - linguistic, theoretical, methodological - which are not absolute since they can change in the course of scientific revolutions. Starting with his first book (Parrini 1976), Parrini develops a relativized and contextualized concept of the a priori and of the distinction between analytic and synthetic judgements.

Parrini develops this view by analysing the rejection of the synthetic a priori by logical empiricists. He highlights the fact that these authors vacillated between different views, before reaching a shared point of view, in line with $\mathrm{H}$. Poincarè, on the linguistic and conventional nature of some general principles that connect the abstract plane of scientific theories with the concrete plane of empirical observation. These principles do not have an empirical content that can be directly verified as they are what makes possible the empirical testing of hypotheses and theories. The standard position of logical empiricists was to assimilate these principles as rules of coordination or correspondence interpreted as linguistic-like conventions. However, Parrini shows that in the 1920s H. Reichenbach proposed a different view, affirming the synthetic-theoretical nature of what he called "constitutive principles". According to Reichenbach at that thime, the general principles that associate theory with experience are synthetic a priori principles. At the same time, these principles are relative to a certain theory and can be revised during scientific revolutions. Reconnecting with Reichenbach's and Pierre Duhem's views, Parrini has thus argued since the 1970's that the constitutive principles are not mere linguistic conventions. On the contrary, they have a theoretical content and an indirect empirical import, being possible to test them in front of the "court of experience". However, this empirical testing is holistic. ${ }^{2}$

\subsection{Holistic empiricism}

The second key concept of Parrini's positive philosophy is holistic empiricism. This is the thesis, taken from Pierre Duhem, according to which our theories go to the court of experience as a whole. In fact, in the light of new experimental results that clash with a given theory (for example Michelson and Morley's experiment in relation to the aether theory, which is at the basis of Einstein's special relativity) experience can declare that there is an implicit contradiction in a theoretical framework (Parrini 2006: 35). Parrini thus argues that we must accept the well-

\footnotetext{
${ }^{2}$ Parrini's view of the relativized a priori must be distinguished from Michael Friedman's view. The latter was developed some decades later and draws on, with some hesitations, the neompiricist thesis of the conventional and linguistic character of the "coordination principles". On this point see (Parrini 2017: 248-249; Westphal 2017: 175).
} 
known thesis of the empirical underdetermination of scientific theories (different logically conceivable theories are compatible with the same complex of empirical data) with the theoretical overdetermination of experience. The latter thesis is explicitly stated by Reichenbach and is implicitly present already in Duhem and claims that experience can show, in a holistic manner, the incompatibility between certain empirical data and a specific theoretical system, without pointing at the specific parts of the theory that are responsible for the empirical inadequacy. ${ }^{3}$

\subsection{Empirical realism}

The third key concept of Parrini's positive philosophy, together with moderate epistemic relativism and holistic empiricism, is empirical realism. Parrini takes up the distinction already introduced by Kant and further developed by Rudolf Carnap, between two concepts of reality: empirical and metaphysical (or absolute, "in itself"). According to logical empiricists, in the light of the principle of verification conceived of as the criterion of meaningfulness, the notion of a metaphysical reality that is absolutely independent from cognitive acts is devoid of meaning. This is because, in principle, this notion cannot be empirically verified. We have seen that Preti drew on this view when criticizing metaphysical realism. On the contrary, Parrini argues that the notion of a metaphysical reality in itself is not meaningless and that it is somehow legitimated by the problem of knowledge (Parrini 2015: 33) and implicit in the way we ordinarily conceive of cognition, within what Husserl calls the natural attitude (see Parrini 2015: 24). For this reason, Parrini claims that the critique of the notion of an absolute reality must be developed on a different, meta-ontological level (Parrini 2015b: 70).

By drawing on Carnap's notion of explication, Parrini argues that a fundamental philosophical task is to elaborate or rationally reconstruct the concepts that we ordinarily make use of in an "unreflective" way. Parrini develops this analysis concerning the main epistemological notions: reality, objectivity, truth and knowledge. In the light of this analysis, he claims that, notwithstanding the fact that the notion of metaphysical reality is not meaningless, from the epistemological point of view it is concretely "inoperative". This is because of the "impossibility of directly comparing it with our beliefs" (Parrini 2015a: 46, my translation). That is, looking at our concrete cognitive practices, when we have to solve dis-

${ }^{3}$ For example, experience alone cannot tell us if within Newtonian physics (with its implicit postulation of absolute space and time and the Euclidean structure of physical space) the "clash" with new experimental data is due to the physical or to the geometrical component. As we know, whereas Lorentz's transformations adapt the laws of optics to the new data (thus preserving the absolute character of space and time), Einstein chooses to turn the constant value of the speed of light into a constitutive principle of the theory of special relativity (thus renouncing the absoluteness of space and time). On these themes see especially (Parrini 2012; 2014). 
putes and disagreements (for instance when two people disagree concerning the alignment of a painting attached to the wall, in an example made by Heidegger), the notion of metaphysical reality is of no use. This is because this notion of reality would be absolutely independent from cognitive practices such as the measurement through instruments (e.g. a spirit level) or the comparison between dream and wakefulness, veridical perception and hallucination. What we can concretely do in our cognitive practices, both ordinary and scientific, is to compare our epistemic claims to a reality that is given within experience and that can be thus known only on the basis of various epistemic presuppositions (linguistic, theoretical and methodological). This analysis leads Parrini to reject the notion of metaphysical reality, which always risks turning into scepticism, in order to develop an epistemological view that is centred on the notion of empirical reality.

At the same time, Parrini also redefines the concepts of truth and objectivity, conceiving of them not in correspondentistic and representational terms but as empty regulative ideals. This means that the notions of truth and objectivity do not have an unchangeable content. They are ideals that guide our cognitive efforts towards syntheses of the empirical data that are more and more broad and inclusive. Drawing on a metaphor from Georg Simmel, Parrini likens the notions of truth and objectivity to "“empty buckets" which are filled at the river of history" (Parrini 1998: 151) and that receive their content from the best theories that we are able to develop at a given time.

Parrini's epistemological view is therefore anti-foundationalist and antiabsolutist, constituting a "third way" - or, better, a "narrow way" (Lecis 2013) between radical relativism and metaphysical realism. This narrow way is aimed at safeguarding the objectivity of our epistemic claims without falling into the absolutization of the object of knowledge, which is always at risk of turning into radical scepticism. At the heart of this view there is an empiricist and a constructivist aspect. The empiricist aspect is contained in the negation of the synthetic a priori when understood in terms of necessary and universal validity. The constructivist aspect consists in acknowledging the crucial cognitive role of principles that are produced by human thinking.

\section{The Phenomenological Way: Empirical Basis and Constitution}

The above seen epistemological view is based on the possibility of empirically testing our theories, notwithstanding the fact that the theoretical constructions that account for experience can change over time. It is in relation to the possibility of empirically verifying our theories that Husserl's phenomenology comes into play at the heart of Parrini's epistemological thought. According to Parrini, Husserl's phenomenology constitutes a "fourth way" that is different from the three ways that Friedman (2000) sees as separating and moving in different directions in $20^{\text {th }}$. 
century philosophy: neokantianism, logical empiricism and Heideggerian hermeneutics. ${ }^{4}$ The "phenomenological way" allows us to address the issue of the empirical basis of knowledge in a specific manner.

\subsection{Husserl and Kant: the cognitive role of intuition}

In order to show the specific features of the "phenomenological way" in Parrini's thought, we can follow, as a guiding thread, the relationship between Husserl and Kant. Parrini highlights the continuity between the Kantian and the Husserlian conceptions of knowledge in terms of an intertwining of form and matter. This is in contrast with the downplaying of the material dimension of knowledge in some neo-Kantians (such as Paul Natorp) and in the logical empiricists (especially Moritz Schlick). To be precise, Parrini highlights the fact that in some reviews in the years 1910-1916 Schlick showed an appreciation of a central theme in Husserl's phenomenology (Parrini 2014: 145 ff.): the essential role of empirical-intuitive components in the process of knowing, as opposed to the downplaying of these elements in some neo-Kantians. According to Schlick, the latter insisted on the formal and conceptual dimension in Kant's analysis of knowledge to the detriment of the material content. However, according to Kant, the material content has an essential role in accounting for the possibility of having knowledge of a particular object (as we know, for Kant concepts without intuitions are empty and the forms of our sensibility synthetically unify a given sensory manifold).

However, in the same years, Shlick strongly criticized the "philosophies of intuition" in authors such as Henry Bergson, Bertrand Russell (with the notion of "knowledge by acquaintance") and Husserl. Concerning the latter, Schlick criticizes the theory of eidetic intuition (Wesensschau) and sets it up against the distinction between Kennen (immediate intuition, understood as a dyadic relation between subject and object) and Erkennen (knowledge, understood as a triadic relation between knower, known, and that through which the known is recognized). This distinction is aimed at denying the cognitive import of intuition, which according to Schlick pertains to the domain of life, which is distinct from knowledge.

However, according to Parrini, Schlick's view does not account for an element of the process of knowing that is essential in the neo-empiricist view, i.e. the empirical-observative dimension that is at the base of the cognitive edifice (and that is expressed by propositions whose problematic status is at the heart of the socalled "protocol-sentence debate"). ${ }^{5}$

\footnotetext{
${ }^{4}$ Friedman refers to the three "ways" that were represented by Ernst Cassirer, Rudolf Carnap and Martin Heidegger at a famous meeting in Davos in 1929. On this theme see (Parrini 2012; 2014; 2017a).

${ }^{5}$ For the comparison between Husserl and Schlick on the theme of intuition see (Lanfredini 2002).
} 
The reference to the phenomenological theory of knowledge has a central role in Parrini's view, which requires that experience provides us with a relatively neutral basis for empirically testing the theories, thus avoiding the drift towards radical relativism due to the strong version of the theory-ladenness thesis (vacuousness of empirical testing and incommensurability of scientific theories). Husserl's phenomenology points out the possibility of accounting for the empirical basis of knowledge, by means of its acknowledgement of the essential role of intuition in the cognitive process.

\subsection{Form and matter}

However, Parrini also highlights some problematic and open aspects of the phenomenological view concerning the relationship between form and matter. These problematic aspects lead us to find a tension between empiricism and constructivism in the phenomenological theory of knowledge (see Parrini 2017a: 7). In order to highlight this tension, we must look in detail at the phenomenological analysis of intuition and, specifically, of perception.

According to Husserl, the perceptual process involves the combination of two elements: intentional form (morphè) and sensory matter (hyle). The concrete perceptual act consists in the intentional "animation" of hyletic contents. However, in par. 85 of Ideas I Husserl raises the problem of defining the precise relationship between these two aspects of experience, asking if we can accept "formless matters" and "stuffless forms" (Husserl 1983: par. 85). In Ideas I, Husserl leaves this issue open, suggesting that the answer requires the "genetic" broadening of phenomenology, by investigating the temporal constitution of experiences. I stress the fact that this open question in phenomenology concerns the possibility of finding a material basis of knowledge that is devoid of any formal element. As we know, in the light of the transcendental arguments, Kant ruled out this possibility: we must exclude the possibility of "judgements of perception" that do not involve the intervention of categories (for example the category of substance in perceiving something that lasts over time or the category of cause in perceiving a temporal succession). In this way, Kant's view is different from reductionist empiricism, which claims to find a pure dimension of experience that is not conditioned by subjective-formal presuppositions.

At this point, we can ask about the position of Husserl's phenomenology in the contrast between Kant's view and reductionist empiricism. From the phenomenological standpoint, we can ask: is it possible to isolate a pure hyletic basis that is absolute, being not dependent on formal conditions (which after the crisis of Kantianism in the light of scientific revolutions could be considered as changeable with the change of conceptual frameworks)?

\subsection{Phenomenology and realism}

The relationship between form and matter is an open issue in Husserl's phenomenology and it crisscrosses the problem of realism. Some central phenomeno- 
logical notions, such as eidetic intuition, material a priori and material ontology could be seen as implying an absolutistic conception of the object of knowledge and in particular of the object of perception and therefore of the "material thing" that appears in perception. This is what is claimed by the so-called "realist" interpretations of phenomenology. According to them, the motto "to the things themselves" refers to the possibility of phenomenologically describing material reality "in itself", independently of the relationship with a knowing subject. However, Parrini criticizes these views, which end up to claim a naïve form of metaphysical realism. In particular, according to some phenomenological realists, material reality is endowed with objective properties that are not only physical-mathematical but also "qualitative" - in contrast with the "scientific" form of metaphysical realism, which conceives of the so-called "secondary" properties as merely subjective appearances. $^{6}$

Parrini's epistemological inquiry leads us to highlight the fact that the notion of reality that is involved in these realist interpretations of phenomenology is the concept of an absolute-metaphysical reality. These views conceive of knowledge as the mirroring of a transcendent reality that is pre-constituted with respect to the cognitive process that leads us to directly know it. However, following Preti's teaching, Parrini highlights the fact that Husserl's phenomenology brings into question the notion of an absolutely transcendent reality (metaphysical reality). This is because the phenomenological inquiry is developed as an "immanent" analysis of the cognitive process and therefore of the correlation between subject and object. In fact, according to Husserl the notion of metaphysical reality involves a "material countersense" (Husserl 1983: 90).?

We must also notice that Husserl develops this critique to the notion of absolutely transcendent reality by referring to the process of "absolutizing Nature as conceived by physics" (Husserl 1983: 101), within scientific realism - or, better,

\footnotetext{
${ }^{6}$ An example of realist phenomenology is Barry Smith's "qualitative ontology" (see Smith 1995; 1999). This view brings together Husserl's phenomenology with James Gibson's ecological theory of perception. The latter, in turn, implies a form of "direct" or "naïve" realism (see Gibson 1967; 1972). However, in contrast with Gibson's direct realism, Husserl's transcendental phenomenology conceives of the object of perception as the correlate of a process of constitution. For this reason, the material thing is not an absolutely transcendent reality with respect to the cognitive process (on this point see Zhok 2013). On the contrary, Smith argues that by combining Husserl's phenomenology with Gibson's ecological theory it is possible to develop "A radically new, realist interpretation of Husserl's 'constitutive phenomenology"” (Smith 1999: 319) and "a new, naturalized interpretation of Husserlian phenomenology" (Smith 1999:317).

${ }^{7}$ On this point and in relation to the crucial concept of motivational links see (Lanfredini 2004).
} 
within the metaphysical version of scientifical realism. ${ }^{8}$ That is, within what Sellars called the "scientific image of the world" (Sellars 1962). In Husserl's view, the scientific image is based on the abstraction of the so-called "primary properties" of the object of experience in order to isolate the component that can be mathematized and idealized. This is the operation through which we construe scientific objectivity and it is valid provided that we don't take "for true being what is actually a method" (Husserl 1970: 51). However, the "naïve" or "common sense" form of metaphysical realism could be conceived of as legitimised by phenomenological notions such as eidetic intuition and material a priori. At the same time, Husserl's critique to the metaphysical hypostatization of the object of physical-mathematical knowledge can be extended to any claim of reaching knowledge of reality considered "in itself", independently of its being constituted as the correlate of a series of cognitive processes. In fact, the phenomenological theory of knowledge claims the relative and not absolute transcendence of the object, which is constituted as the correlate of constitutive functions of subjectivity. Therefore, following Kant, Husserl seems to reject all forms of metaphysical realism, admitting the empirical and not metaphysical reality of the object of experience within a correlative analysis of knowledge.

\subsection{Kant's concept of truth}

Parrini addresses the issue of realism in phenomenology by analysing some Heideggerian passages, where the author of Being and Time seems to argue for a phenomenologically based form of metaphysical realism. Parrini contrasts these passages with a specific interpretation of Kant's concept of truth. Drawing on the above-seen example, Heidegger considers two people that turn towards a wall to verify the truth-value of the judgement according to which a painting is hanged crookedly. According to Heidegger, when I turn towards the wall I am not directed towards mental representations. On the contrary, I am directed towards the "thing itself" that, in this way, is directly known (see Parrini 2017a: 8). However, Parrini argues against Heidegger that, notwithstanding the fact that we are directed towards the wall and the painting, the truth-value of our judgements concerning the alignment of the painting depends on their congruence with a set of principles that are at the basis of the constitution of cognitive objectivity. For instance, I must make use of measurements, which are based on a set of constitutive principles that are relatively a priori (see Parrini 1994). Furthermore, I must compare and synthesize different experiences in order to verify that I am really perceiving the painting and I am not dreaming or having a hallucination.

Parrini thus opposes a specific reading of the Kantian concept of truth to the naïve or direct realism that is expressed in the above seen Heideggerian passages (Parrini 1994). He does so by distinguishing between nominal definition and the

\footnotetext{
${ }^{8}$ On the distinction between an empirical and a metaphysical version of scientific realism see (Parrini 2002: 61). See also (Parrini 1998: 115 ff.).
} 
criterion of the truth of the judgement. In giving the nominal definition, Kant draws on the traditional concept of truth as the agreement of a cognition with its object. However, the crucial point is to define the criterion through which we can evaluate the alleged truth of our judgements. According to Kant, in the case of empirical judgements this criterion consists in its agreement not only with material conditions (a given sensory manifold) but also with formal conditions. These formal conditions of truth consist in the conformity of the judgement with a series of operations through which we establish, for example, the difference between veridical perception and hallucination or between wakefulness and dream. In fact, according to Kant the difference between dream and wakefulness is not found in the material content of the representations (which can be identical in both cases). The difference is found in the agreement or not of these representations with the principles that rule correct judgement and that constitute, at the same time, the conditions of possibility of experience.

Kant argues that knowing does not mean to faithfully mirror a pre-constituted reality but it means to unify a given sensory manifold through constitutive functions of subjectivity. This constructivist element in Kant's view is in part present also in Husserl's phenomenology. Also according to Husserl, in order to establish the truth of our cognitive claims and therefore their reference to empirical reality, we must insert the individual manifestation in the context of a series of experiences that are motivated and concordant to one other. The criterion of truth is found in the genetic-motivational connection between phenomena (Husserl 1983: 89; see also Lanfredini 2004: 171; 2006: 91-93; 2012: 411-412). This is the connection that breaks up in dreams and hallucination, where the experiential course turns out to be full of gaps and inconsistencies. Therefore, in Husserl's view, the immediate presence of an hyletic datum (e.g. a sensation of red) is not sufficient for perceiving an object (e.g. a red cherry). Perceiving requires the intentional animation of hyletic contents within a coherent experiential course, through which the material thing is constituted as the unitary correlate of an experiential synthesis. This is a constructivist element, of a Kantian origin, in the phenomenological conception of the constitution as correlation subjective-objective, which leads us to claim the empirical and not metaphysical reality of the object that is transcendent to consciousness.

\subsection{The material a priori}

The issue of realism in phenomenology is strictly linked to the notion of material a priori. This notion seems to refer to the possibility of having a priori knowledge (i.e. universal and necessary knowledge) of the content or matter of knowing, which would be expressed through apodictic judgements. Parrini discusses the epistemological features of these judgements that, according to Husserl, would express the necessary connection between material contents of experience (e.g. the relationship of bilateral foundation between color and extension of a vis- 
ual object, or between timbre and duration of a sound). According to Parrini, considering the synthetic (i.e. informative) character of these judgements and their a priori character (i.e. universal and necessary validity) leads us to ask if they clash with the same criticisms that have been raised against Kant's concept of synthetic a priori in the light of scientific revolutions. According to Kant, the demonstration of the universal and necessary validity of synthetic a priori judgements is a normative and not factual matter. These judgements have a de jure and not de facto validity, which is demonstrated by the transcendental arguments of the Critique of Pure Reason. As is known, Kant's transcendental turn consists in reaching the level of normativity in epistemology. The normativity of synthetic a priori judgements comes from the fact that they express the conditions without which experience (be it "internal" or "external") would not be possible (e.g. the perception of permanence over time or the temporal succession of phenomena). However, subsequent scientific developments have attacked Kant's claim of having established conditions of possibility of experience that are given once for all and that are unchangeable.

Is it the same concerning Husserl's material a priori judgements? Should we acknowledge their revisability and therefore their non-apodicticity? A phenomenological answer to this objection can consist in claiming that, with this notion in mind, Husserl refers to the essential structure of sensory givenness (e.g. the essential connection between color and extension) and that this givenness does not require the intervention of concepts. On the contrary, it requires an intuitive unification (Lanfredini 2006). Therefore, being not pertaining to the conceptual level, the material a priori judgements are not subject to revisions induced by theoretical changes. However, Parrini observes that this line of argument leads us to an outcome that is different from Kant's view, limiting us to the claim of a merely psychological-subjective validity and not a transcendental validity in the Kantian sense (Parrini 2006: 37). This is because the material a priori judgements are not based on a transcendental deduction (which Kant conceives of in a juridical sense, being aimed at demonstrating the validity in principle of certain propositions and not their merely factual validity). For this reason, the material a priori judgements would express the structure of human sensibility, being essentially dependent on factual-contingent presuppositions. In this way, material a priori judgements would express a validity that is "a priori" only for beings that have certain factual features and not others. ${ }^{9}$ However, this conclusion goes against the realistic interpretations of phenomenological ontology, which aim at grasping the essential features of an absolutely transcendent reality (i.e. metaphysical reality). On the contrary, this conclusion leads us to acknowledge the factual basis of the constitution of experience and of the reality that is constituted as its correlate, thus leading us

9 Parrini stresses the presence of this fluctuation between the factualpsychological level and the normative level also in Kant, in relation to the individuation of the forms of sensibility and in the way of framing the transcendental deduction of the categories (see Parrini 1994). 
to a phenomenological concept of empirical reality, i.e. a phenomenological form of empirical realism.

\section{Lines of development of phenomenology in the light of positive philosophy}

In this section, I shall point out some lines of development of the phenomenological form of empirical realism that emerges from Parrini's positive philosophy.

\subsection{Genetic and embodied phenomenology}

Parrini's problematization of the notion of material a priori is compatible with a line of development of phenomenology that we can find, firstly, in Husserl himself and, secondly, in Merleau-Ponty. In fact, within the so-called "genetic" broadening of phenomenology, Husserl develops an embodied conception of consciousness that acknowledges the bodily grounding of consciousness and its worldly and intersubjective dimensions (for instance in Husserl 2001; 1989; 1969). In the context of this research, Husserl argues for the essential role of certain bodily structures and functions in the constitution of experience in its polarity subjectiveobjective. In fact, the phenomenological analysis of the living body (Leib) leads us to highlight the constitutive role of structures and functions that depend on the specific bodily constitution of a living being. These factual features are, at the same time, presuppositions of the constitution, therefore a priori, with a contingent status. In Formal and Transcendental Logic, Husserl introduces the concept of contingent a priori (Husserl 1969: 26). The analyses of facticity in genetic phenomenology investigate how the intentional animation of sensory matter depends on the factual constitution of the living body. In this way, the perceptual abilities of a living being turn out to be dependent on its bodily features (its embodiment). These contingent a priori conditions concern both matter and form of perceptual experience, which turn out to depend on the factual constitution of an embodied consciousness. ${ }^{10}$

Therefore, the phenomenological analyses of corporeality develop in a preconceptual and embodied direction the concept of knowledge as constitution. From the standpoint of genetic phenomenology, the primary constitution of objectivity does not require the use of concepts (conceived of as linguistic-propositional entities). On the contrary, it requires certain forms of sensibility, conceived of as a priori presuppositions that are relative to the corporeal constitution of the living subject.

This phenomenological analysis of the relative a priori status of bodily structures in the genesis of experience can be also found in Maurice Merleau-Ponty. Samantha Matherne (2016) argues that, with his analysis of the concept of body

\footnotetext{
${ }^{10}$ On this point, see especially the analyses of the role of the living body in the
} process of constitution in Ideas II. 
schema, Merleau-Ponty develops in a non-intellectualist way Kant's doctrine of the schematism. At the same time, Merleau-Ponty redefines the notions of transcendental and a priori, seeing in them the expression of "formal features of our facticity, without which there would be no experience" (Matherne 2016: 207). This view is coherent with Husserl's notion of the "contingent a priori", claiming that the a priori forms depend on factual features of an embodied subjectivity. ${ }^{11}$

However, Parrini's epistemological view leads us to make a clarification, especially in relation to the contemporary attempts at "naturalizing phenomenology". In fact, the phenomenological analysis of facticity and corporeality must not be confused with an alleged naturalization of phenomenology. "Transcendental" phenomenology is, first of all, a critique of knowledge. Therefore, it is developed on an epistemological and not factual-psychological level. This means that the phenomenological analysis of facticity must be conceived as a development of the theory of knowledge that investigates the fundamental correlation between subject and object in the cognitive process. It is on the basis of this fundamental specification that we can investigate the factual presuppositions of the constitution, reaching a phenomenologically adequate conception of notions such as nature, body and living being. ${ }^{12}$ This is done within a correlative analysis, which looks at the co-constitution of subject and object in reciprocal dependence in the process of experience. Therefore, this inquiry must not be confused with the hypostatization of the region "nature" within certain attempts at "naturalizing" the mind and phenomenology, which end up conceiving of nature as a fundamental metaphysical dimension to which subjectivity could be traced back to. ${ }^{13}$

\subsection{Phenomenology and the network model}

The genetic and embodied direction of inquiry in phenomenology combines empiricism and constructivism in the analysis of knowledge. A significant epistemological implication of this line of inquiry is that the embodied a priori forms are

11 This development of phenomenology in a genetic and embodied direction is also at the base of the "enactive" approach developed by (Varela, Thompson, and Rosch 1991). On this point see (Pace Giannotta 2017).

12 See Pace Giannotta (2018) for the concept of empirical naturalism, as opposed to metaphysical naturalism, which is based on the phenomenological form of empirical realism.

13 Parrini stresses the distinction between the "epistemologic" and the "scientific-naturalistic" planes, in constrast with the attempts at "naturalizing epistemology". According to Parrini, the prospective success of such a project, which is "doubtful" and "far from being realized", would mean that "not only epistemology, conceived of as the analysis of the conditions of validity of our cognitive claims, but also ontology, conceived of in the terms of the problem of realism and anti-realism would disappear; only natural science would remain" (Parrini 2015a: 49, my translation; see also Parrini 2015b: 75). 
pre-conceptual. These forms are conditions of possibility of conceptualization; however, they do not univocally predetermine conceptualization, since they do not force the experience into fixed conceptual frameworks that are set forever. In this way, it becomes possible to account for two aspects of knowledge that are central in $20^{\text {th }}$-century epistemology: the theory-ladenness of observation and the revisability of theories and conceptual frameworks.

We have seen that Parrini's positive philosophy constitutes an alternative to the radical relativism that would follow on from the strong version of the theoryladenness thesis. In order to do so, it must be possible to test different theories in order to choose the one that is more compatible with experimental results. According to Parrini, this possibility is guaranteed by the "network model" of knowledge that has been developed by Mary Hesse (Hesse 1974; see also Lanfredini 1988; Parrini 1998: 74 ff.).

The network model acknowledges at the same time the theory-ladenness of observation and the possibility of finding areas of empirical intersection between competing theories in order to test and compare them. This objective is obtained through a revision of the empiricist theory of concept-formation. Hesse's "new empiricism" takes up from Quine the concept of an innate and prelinguistic "quality space", which accounts for the innate power of the human mind to recognize similarities and differences between different situations by "weighing" the features that appear in experience differently and on the basis of tacit criteria. ${ }^{14}$ The "primary process of recognition of similarities and differences" (Hesse 1974: 13) is at the basis of the formation of scientific language and allows us to find areas of empirical intersection between different theories. These differences are revealed by the linguistic behaviour of speakers in front of a certain phenomenon. For example, we can refer to Michelson's and Morley's experiment: there is a phenomenon - the vision or not of an interference pattern through the interferometer - that is conceptualized differently within different theories (the aether theory or Einstein's special relativity). However, we can say that the proponents of different theories share a common and basic phenomenal experience.

I would like now to higlight some significant points of contact between Hesse's network model and phenomenology. In fact, they both develop a sophisticated analysis of the empirical basis of knowledge. However, we have also seen that Husserl's theory of eidetic intuition could be interpreted in absolutistic terms, within the realist interpretations of phenomenology. On the contrary, the genetic and embodied development of phenomenology investigates the bodily forms that are contingent a priori presuppositions of the constitution, thus limiting the alleged metaphysical implications of the doctrine of eidetic intuition. In accordance with the network model, this analysis leads us to claim the pre-conceptual nature of the empirical basis. The genetic-phenomenological analysis of the a priori forms of sensibility, conceived in bodily and pre-conceptual terms, accounts for the conditions of possibility of those primary recognitions of similarities and differences

\footnotetext{
${ }^{14}$ For the details of this analysis see (Parrini 1998: $74 \mathrm{ff}$.).
} 
that the network model founds at the basis of concept-formation. Quine conceived of the notion of "quality space" as the "minimal" innatist requirement of his empiricist view. This notion is taken up by Hesse's network model and it is coherent with the phenomenological analysis of the qualitative structure of experience. However, this structure must not be conceived of as the structure of an alleged reality in itself (metaphysical realism). On the contrary, it must be understood in the light of the phenomenological empirical realism, which is developed as an analysis of the correlation and co-constitution of subject and object in reciprocal dependence.

\subsection{Phenomenology and neutral monism}

Parrini's analysis of the concepts of reality and truth also allows us to better understand another possible development of embodied and genetic phenomenology. This inquiry goes to the core of the constitution of the life of consciousness in the stream of primal impressions (Urimpressionen). This inquiry can be further developed by conceiving the impressional core of experience as a fundamental "ontological" dimension that precedes the constitution of subject and object. This is because, by investigating the "genesis of constitution" (Husserl 2001: 644), genetic phenomenology investigates the co-constitution of the subject and the object in reciprocal dependence. In the light of this analysis, the process through which a certain object is constituted turns out to be the process through which the subjective pole of cognition is also constituted.

In this way, the phenomenology of genesis turns out to be close to the view known as neutral monism. This is the view pioneered by philosophers such as Ernst Mach, William James and Bertrand Russell and that is nowadays the object of reassessment in various sectors of contemporary philosophy..$^{15}$ However, in the light of its rational reconstruction of the concepts of reality, truth and objectivity, Parrini's epistemological inquiry allows us to distinguish between different forms of neutral monism. In particular, we can distinguish Mach's doctrine of the "neutral elements" from the subsequent development of neutral monism as a form of metaphysical realism in authors such as James and Russell. This interpretation of Mach's view contrasts with Erik Bank's interpretation, which stresses the continuity between Mach, James and Russell and conceives of Mach's view as a philosophy of nature and as a metaphysics of neutral elements. According to this reading, Mach finds in the "elements" a fundamental metaphysical dimension that is presubjective and pre-objectual, by conceiving of the subject and the object as constructions from complexes of elements. However, Parrini (2017c) stresses the fact that Mach conceived of this view as a scientific and not metaphysical hypothesis, which aims at investigating the relationship between two scientific disciplines: physics and psychology. Mach thus develops his "neutral monism" with a sharp criticism to the absolutistic claims of metaphysics. For this reason, Parrini warns

${ }^{15}$ See (Banks 2003; 2010; Stubenberg 2014). 
us against the temptation of making the metaphysical "leap" that consists in conceiving of the pre-subjective and pre-objectual dimension of experience as a "fundamental", "absolute" or "ultimate" reality that is absolutely independent from contingent presuppositions of the cognitive process.

In this way, Parrini's reading of Mach's philosophy points to the possibility of conceiving of neutral monism as a scientific-philosophical hypothesis that sets out a general and non-metaphysical conception of reality. This is in accordance, again, with the phenomenological empirical realism that is revealed by Parrini's positive philosophy. ${ }^{16}$

\section{References}

Banks, Erik C. 2003. Ernst Mach's World Elements. A Study in Natural Philosophy. Dordrecht: Springer. . 2010. "Neutral Monism Reconsidered." Philosophical Psychology 23 (2): 173-87.

Friedman, Michael. 2000. A Parting of the Ways. Carnap, Cassirer, and Heidegger. Chicago and La Salle, Illinois: Open Court.

Gibson, James J. 1967. "New Reasons for Realism.” Synthese 17 (2): 162-72.

- 1972. "A Theory of Direct Visual Perception." In The Psychology of Knowing, edited by J. R. Royce and W. W. Rozeboom. New York: Gordon \& Breach.

Hesse, Mary. 1974. The Structure of Scientific Inference. Berkeley - Los Angeles: University of California Press.

Husserl, Edmund. 1969. Formal and Transcendental Logic. The Hague: Martinus Nihoff.

- 1970. The Crisis of European Sciences and Transcendental Phenomenology. Evanston: Northwestern University Press.

. 1983. Ideas Pertaining to a Pure Phenomenology and to a

${ }^{16}$ In the light of this analysis we can also look at the phenomenological conception of scientific objectivity. Husserl's criticism of the absolutization of Nature as the object of physics is in accordance with Parrini's criticism to the metaphysical version of scientific realism, which would presuppose an absolutistic conception of reality. Husserl conceives of the object of natural-mathematical science as the object of a sort of second order constitution, which is based on the primary constitution of the material thing in ordinary experience. The latter, in turn, doesn't give us access to an alleged metaphysical reality "in itself". The phenomenological view of experience is therefore centred on the fundamental correlation and coconstitution of the two poles of the cognitive process. At the same time, it is compatible with the empirical and not metaphysical version of scientific realism, which acknowledges the empirical reality of the entities posited by natural science (see Parrini 1998: 32, 115 ff.; Parrini 2002: 61). 
Phenomenological Philosophy. First Book: General Introduction to a Pure Phenomenology. Edited by F. Kersten. The Hague: Martinus Nihoff.

. 1989. Ideas Pertaining to a Pure Phenomenology and to a Phenomenological Philosophy. Second Book: Studies in the Phenomenology of Constitituion. Edited by Richard Rojcewicz and André Schuwer. Dordrecht: Kluwer Academic Publishers.

- 2001. Analyses Concerning Passive and Active Synthesis: Lectures on Transcendental Logic. Edited by Anthony J. Steinbock. Dordrecht: Springer.

Lanfredini, Roberta. 1988. Oggetti e paradigmi. Per una concezione interattiva della conoscenza scientifica. Roma: Theoria.

—. 2002. "Conoscibilità del contenuto: forma e intuizione in Schlick e Husserl." In Forma e contenuto. Aspetti di teoria della conoscenza, della mente e della morale, edited by Roberta Lanfredini, 67-84. Milano: LED. - 2004. "Fenomeno e cosa in sè. Tre livelli di impossibilità fenomenologica." In Fenomenologia applicata. Esempi di analisi descrittiva, edited by Roberta Lanfredini. Milano: Guerini.

- 2006. "La nozione fenomenologica di dato." In A priori materiale. Uno studio fenomenologico, edited by Roberta Lanfredini, 59-94. Milano: Guerini.

- 2012. "Fenomenologia e epistemologia." In Storia della fenomenologia, edited by Antonio Cimino and Vincenzo Costa, 395-416. Roma: Carocci.

Lecis, Pier Luigi. 2013. "La via stretta tra realismo metafisico e relativismo radicale." In A Plea for Balance in Philosophy. Essays in Honour of Paolo Parrini, edited by Roberta Lanfredini and Alberto Peruzzi, 253-68. Pisa: ETS.

Matherne, Samantha. 2016. "Kantian Themes in Merleau-Ponty's Theory of Perception." Archiv Fur Geschichte Der Philosophie 98 (2): 193-230.

Pace Giannotta, Andrea. 2017. "Varela on the Pragmatic Dimension of Phenomenology." Constructivist Foundations 13 (1): 78-81.

$$
\text { (2). }
$$

Parrini, Paolo. 1976. Linguaggio e teoria. Due saggi di analisi filosofica. Firenze: La Nuova Italia.

. 1994. "On Kant's Theory of Knowledge: Truth, Form, Matter.” In Kant and Contemporary Epistemology, edited by Paolo Parrini, 195-230. Dordrecht: Springer.

. 1998. Knowledge and Reality. An Essay in Positive Philosophy. Dordrecht: Kluwer Academic Publishers.

. 2002. Sapere e interpretare. Per una filosofia e un'oggettività senza fondamenti. Milano: Guerini.

- 2006. "A priori materiale e forme trascendentali della conoscenza. Alcuni interrogativi epistemologici." In A priori materiale. Uno studio fenomenologico, edited by Roberta Lanfredini, 15-39. Milano: Guerini. 
2011. Il valore della verità. Milano: Guerini.

2012. "Fenomenologia ed empirismo logico." In Storia della fenomenologia, edited by Antonio Cimino and Vincenzo Costa, 81-110. Roma.

. 2014. "About the 'Parting of the Ways': Three Roads or Four?" Philinq II (2): 141-59. doi:10.1093/pastj/gti009.

. 2015a. "Il problema del realismo dal punto di vista del rapporto soggettooggetto." In Realtà, verità, rappresentazione, edited by Pier Luigi Lecis, Vinicio Busacchi, and Pietro Salis, 21-51. Milano: Franco Angeli.

- 2015b. "Ontologia e epistemologia." In Architettura della conoscenza e ontologia, edited by Roberta Lanfredini, 39-77. Milano: Mimesis.

- 2017a. "A Priori, Objectivity, and Judgement. Crossing the Paths of Kantianism, Phenomenology and Neo-Empiricism: A Tribute to Giulio Preti." Diogenes 61 (2): 59-72. doi:10.1177/0392192116679300.

- 2017b. "Epistemologia e approccio sistemico." Rivista di filosofia neoscolastica 2 (2017): 239-53.

- 2017c. "Introduzione. Mach scienziato-filosofo." In Ernst Mach, Conoscenza ed errore. Abbozzi per una psicologia della ricerca, 7-54. Milano - Udine: Mimesis.

Preti, Giulio. 1974. "Lo scetticismo e il problema della conoscenza." Rivista critica di storia della filosofia 29: 3-31, 123-43, 243-63.

Sellars, Wilfrid. 1962. "Philosophy and the Scientific Image of Man." In Frontiers of Science and Philosophy, edited by Robert Colodny, 35-78. Pittsburgh: University of Pittsburgh Press.

Smith, Barry. 1995. "The Structures of the Common-Sense World." Acta Philosophica Fennica 58: 290-317.

. 1999. "Truth and the Visual Field." In Naturalizing Phenomenology: Issues in Contemporary Phenomenology and Cognitive Science, edited by Jean Petitot, Francisco J. Varela, Bernard Pachoud, and Jean-Michel Roy, 317-29. Stanford (CA).

Stubenberg, Leopold. 2014. "Neutral Monism." Stanford Encyclopedia of Philosophy Fall 2014.

Varela, Francisco J., Evan Thompson, and Eleanor Rosch. 1991. The Embodied Mind: Cognitive Science and Human Experience. Cambridge, MA: MIT Press.

Westphal, K. 2017. "Empiricism, Pragmatic Realism, and the A Priori in Mind and The World Order." In Pragmatism in Transition, edited by Peter Olen and Carl Sachs, 169-98. London: Palgrave Macmillan.

Zhok, Andrea. 2013. "On the Reality of Percepts: Husserl and Gibson." Phenomenology and Mind 4: 46-53. 